\title{
\#FEMINISM: HASHTAG FEMINISM AND THE LOGIC OF CONNECTIVE ACTION
}

\author{
Jacqueline Stevens \\ BA, McGill University, 2018 \\ Supervisor: Dr. Robert Clapperton
}

The Major Research Paper is submitted in partial fulfillment of the requirements for the degree of Master of Professional Communication at Ryerson University

\author{
Ryerson University \\ Toronto, Canada 2019 \\ Jacqueline Stevens 2019
}




\section{AUTHOR'S DECLARATION FOR ELECTRONIC SUBMISSION OF A MAJOR RESEARCH PAPER}

I hereby declare that I am the sole author of this MRP. This is a true copy of the MRP, including any required final revisions.

I authorize Ryerson University to lend this MRP to other institutions or individuals for the purpose of scholarly research.

I further authorize Ryerson University to reproduce this MRP by photocopying or by other means, in total or in part, at the request of other institutions or individuals for the purpose of scholarly research.

I understand that my MRP may be made electronically available to the public. 


\begin{abstract}
Cyberactivism describes the ways in which the internet and social media platforms enable users to become activists. Hashtag feminism has become an integral form of cyberactivism which promotes gender equality and fights against today’s most prominent women's issues. Focusing on the hashtags \#Feminist, \#Feminism, and \#Genderequality, this major research project uses Social Network Analysis (SNA) to examine hashtag feminism networks on Twitter in relation to the logic of connective action. The research questions of this paper explore the density, centralization, modularity and cluster characteristics of hashtag feminism networks, and question whether feminist hashtags are implemented by members of countermovements. In addition, this paper references Habermas's theory of the public sphere to ground the analysis of hashtag feminism. The results of the network analysis suggests that Twitter may serve as a counterpublic in which both feminists and anti-feminists can produce and participate in discourses that represent their interests and identities. Additionally, the analysis found that organizations tend to hold the most dominant role in hashtag feminism Twitter networks.
\end{abstract}




\section{ACKNOWLEDGEMENTS}

I would like to thank Dr. Robert Clapperton for providing me with valuable support, guidance, academic expertise, and constructive recommendations throughout this project. I would also like to thank Dr. John Shiga for serving as second reader, whose input was very helpful and appreciated. 


\section{TABLE OF CONTENTS}

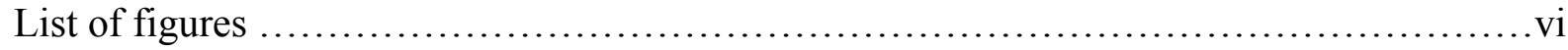

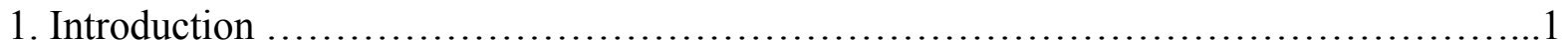

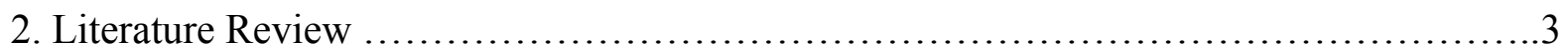

2.1 Cyberactivism and the Logic of Connective Action ..............................

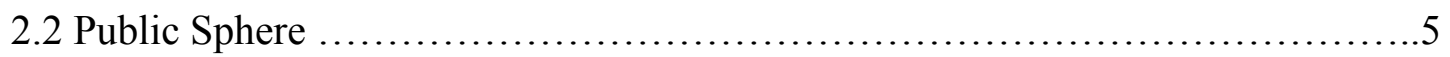

2.3 Hashtag Feminism ....................................................... 10

2.4 Social Network Analysis ...............................................11

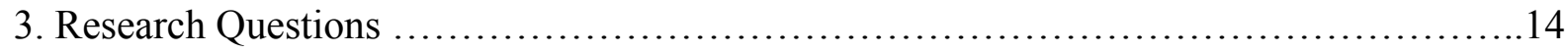

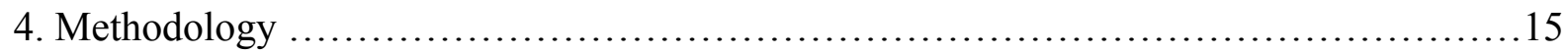

4.1 Data Collection Approach ..................................................15

4.2 Method of Analysis ......................................................... 16

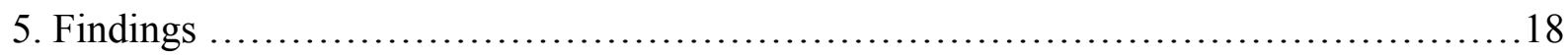

5.1 Research Question 1 Findings .............................................. 18

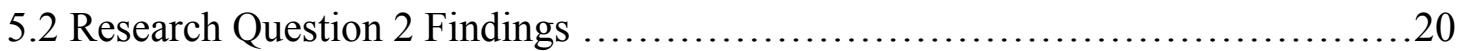

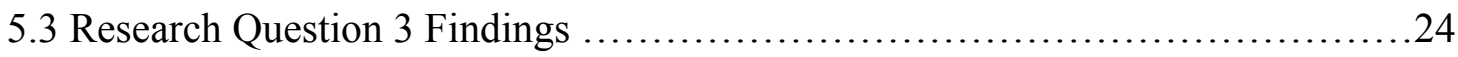

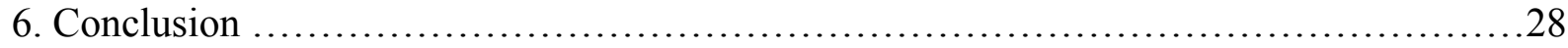

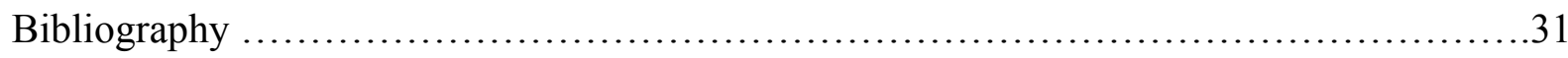




\section{LIST OF FIGURES}

Figure 1: Overall hashtag feminism Twitter network ................................ 19

Figure 2: Comparison of visualization based on indegree vs. outdegree $\ldots \ldots \ldots \ldots \ldots \ldots \ldots . . .22$

Figure 3: Main clusters in overall hashtag feminism Twitter network ....................22

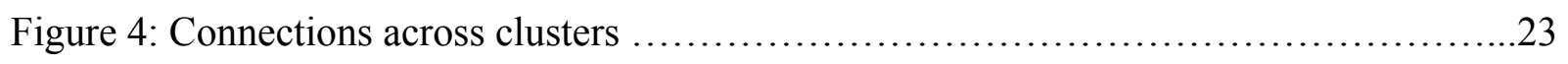

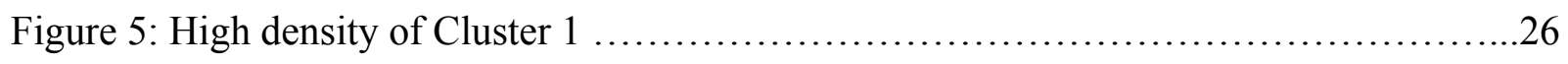




\section{INTRODUCTION}

Cyberactivism describes the ways in which the internet and social media platforms enable users to become activists. As exemplified by recent cyberactivism movements such as Black Lives Matter and the 2017 Women's March, it is clear that social media platforms are changing the ways in which activists take action in today's digital world.

Hashtag feminism has become an integral form of cyberactivism which promotes gender equality and fights against today's most prominent women's rights issues such as unequal pay, violence against women, and rape culture. Hashtags such as \#YesAllWomen, \#GenderEquality, and \#WhyIMarch have been used on Twitter by women and men from all over the world, from regular citizens to prominent politicians and celebrities, to spark and disseminate meaningful discussion surrounding the rights of women. Modern technology, such as social media platforms like Twitter, Facebook and Instagram, have allowed people to participate in activism today more than ever, which has important implications for understanding how people connect and share information. Studying hashtag feminism can uncover crucial insights into these implications, and shed light on how the average citizen can contribute to a cause they care deeply about.

This major research project will use Social Network Analysis (SNA) to examine hashtag feminism networks on Twitter in relation to the logic of connective action. In short, the logic of connective action suggests that connective action is produced through the sharing of 'personal action frames' via the organizational networks of social media (Bennet \& Segerberg, 2012). The research questions of this paper will explore the density, centralization, modularity and cluster characteristics of hashtag feminism networks, and question whether feminist hashtags are implemented by members of countermovements. In addition, Habermas's theory of the public 
sphere will be referenced to ground this analysis of hashtag feminism, as it provides a strong basis for understanding how everyday people participate in activism and politics. 


\section{LITERATURE REVIEW}

This literature review explores definitions, theories and studies related to cyberactivism, the logic of connective action, hashtag feminism, and the public sphere.

\subsection{Cyberactivism and The Logic of Connective Action}

Cyberactivism involves the use of Internet-based platforms and technologies in activist activities aimed to bring about social or political change. In their article discussing how technology has contributed to shaping modern activism, Sandoval-Almazan \& Gil-Garcia (2014) describe cyberactivism in relation to the varying capabilities of Web 1.0 and Web 2.0, distinguishing two forms of cyberactivism: cyberactivism 1.0 and 2.0, respectively. Cyberactivism 1.0 makes use of primary Internet capabilities such as e-mail and websites to recruit members, content update occurs with medium speed, and interaction between activists occurs both online and offline. Examples of cyberactivism 1.0 include culture jamming, sit-in activism, and hacktivism (Sandoval-Almazan \& Gil-Garcia, 2014). This project will focus on cyberactivism 2.0, which involves the use of social media platforms such as Facebook and Twitter in cultivating and executing activist pursuits. Cyberactivism makes use of the capabilities of web 2.0 and involves self-organized collective activity. In addition, in cyberactivism 2.0, content update occurs instantaneously and is permanent, online recruitment is continuous, and most interaction between activists occurs online (Sandoval-Almazan \& Gil-Garcia, 2014).

Many prominent theories have been modified to account for the changes that technology and social media bring to activism and social and political relations. One theory that has been adapted by multiple scholars to account for the ever-increasing use of technology in activism surrounds the logic of collective action. In their 2012 article, Bennet \& Segerberg (2012) explain 
how the production of collective action in social movements has changed over time. In the past, the organization of social movements was normally facilitated by hierarchical organizations, who encouraged the production of collective action through "common banners and collective identity frames" which were shared and spread throughout populations through education and socialization processes (Bennet \& Segerberg, 2012, p. 742). The authors argue that in contrast to the traditional production of collective action via the influence of hierarchical organizations, social movements in today's individualistic, digital society produce "connective" action, which stems from the sharing of 'personal action frames' through the organizational networks of social media. Personal action frames are characterized by two important elements. First, personal action frames contain "political content in the form of easily personalized ideas", and second, the sharing of personal action frames is enabled by communication technologies and social media platforms such as tweets, texts, instant messages, and videos (Bennet \& Segerberg, 2012, p. 744). Distinct from traditional collective action-based social movements, modern social movements characterized by connective action networks can scale up and grow very quickly, as technologies like social media platforms enable the speedy circulation of personal action frames (Bennet \& Segerberg, 2012).

In their article, Bennet \& Segerberg (2012) propose a 3-part typology of large-scale action networks, including organizationally brokered networks, which are characterized by collective action, and self-organizing networks and organizationally enabled networks, which are both characterized by connective action. For the purposes of this paper, the definitions of the latter two connective action networks are helpful to explore the different types of connective action that is produced in cyberactivist movements. In self-organizing networks, technologies such as social media platforms act as organizational agents, allowing members of social 
movements to self-organize into networks, in which personal action frames are shared. Organizationally enabled networks are a hybrid form of connective action networks, in which formal organizations are loosely present, moderating the sharing of personal action frames through various social technologies. The goal of organizations in these networks is to engage individuals and garner membership for a social cause without projecting "strong agendas, political brands, and collective identities" the organization may hold (Bennet \& Segerberg, 2012). Many NGOs follow this hybrid model, minimizing their organizational branding, while making use of communication technologies like Twitter to motivate publics to interact and take action collectively.

\subsection{Public Sphere}

Jurgen Habermas's (1991) conception of the public sphere is especially relevant in cyberactivism research, as it provides a basis for understanding how everyday citizens participate in activism and politics. Although the central theory of this project surrounds the logic of connective action, public sphere theory will be referenced to ground my analysis of the cyberactivist phenomenon of hashtag feminism. In his seminal description of the public sphere, Habermas (1991) describes it as the space in which citizens form public opinion and engage in discourse about matters of society, politics, and the economy. Habermas (1991) outlines two necessary conditions of the public sphere: first, the public sphere is a space in which no person's opinion is above another's, and second, the public sphere is open and accessible to all.

There are two general camps in existing scholarship that relate social media to Habermas's public sphere theory: the anti-social media camp suggests that social media use and online activism does not advance discursive activity within the public sphere, while the pro- 
social media camp suggests that social media and online activism do advance citizens' political participation within the public sphere.

Firstly, the anti-social media literature will be discussed, which points to evidence that social media and online activism do not contribute to political participation, and fail to strengthen the public sphere. Habermas's (1991) specifications of the public sphere have been viewed as utopic, unrealistic, and exclusionary by many prominent feminists and other activism scholars. Feminist scholar Nancy Fraser (1990) argues that contrary to Habermas's original idea, the public sphere is not an equal space. Rather, marginalized groups such as black people, women, gay people, and lesbians are excluded from participating in the primary public sphere (Fraser, 1990). Fraser (1990) suggests that this exclusion from the primary public sphere encourages subordinated groups to form counter-publics, alternative discursive spaces in which they can produce counter-discourses that represent their identities and interests. Those who make up such counter-publics are linked by their concern to establish new forms of social and political relations that resist the inequality of power in the dominant public sphere (McLaughlin, 1993). Both Fraser (1990) and Charles \& Fuentes-Rohwer (2015) argue that counter-publics expand the discursive space, and promote member diversity in political discourses. Although Habermas's conception of the public sphere is considered ideal and unrealistic by Fraser (1990) and many other important scholars, his theory serves as an important starting point for examining the varying ways that individuals and marginalized groups participate in activism.

Kruse, Norris \& Flinchum (2018) performed in-depth interviews with Millennials and Generation Xers to explore whether social media engages people in communicative action that can enhance the public sphere. The authors introduce communicative action as a concept from Habermas that refers to "respectful and open communication, without intimidation, aimed at a 
common goal of finding the truth" (Kruse, Norris \& Flinchum, 2018, p. 63). This study found little evidence that communicative action occurs on social media, and suggests that citizens avoid partaking in political discussions online due to fears of conflict and workplace surveillance (Kruse, Norris \& Flinchum, 2018). Thus, without meaningful communicative action and political discussion online, the public sphere is not advanced.

Scholars such as Christensen (2011) have coined the term "slacktivism" to describe social media activity that has no real influence in increasing offline political participation and contributing to the public sphere, only serving to "increase the feel-good factor of the participants" (p. 1). Liking, sharing or retweeting someone else's politically-driven posts, or clicking "attend" to a political event in order to feel like part of the movement are examples of slacktivism. A study by Lyba (2017) set out to explore how social media usage patterns among young people are related to their real-life political participation. This study found that exposure to political content on social media platforms is only weakly associated with offline political activist behavior; instead, it is strongly linked to slacktivist behavior (Lyba, 2017).

Scholars in the pro-social media camp examine how the affordances of social media are used in activism, and argue that this use can lead to greater and more diverse participation of citizens in the public sphere. Shirky (2016) highlights how social media is a powerful tool that can strengthen the public sphere, arguing that social media tools are critical means by which political opinion is developed and publicly shared throughout people's interpersonal networks.

Scholar Nikita Carney's (2016) article analyzing Twitter content related to the Black Lives Matter cyberactivist movement demonstrates how social media platforms like Twitter can give previously excluded citizens access to the public sphere, allowing them to better participate in political discussion. Carney (2016) argues that social media platforms provide young black 
men with an emerging form of access to the public sphere, which allows them to actively participate and contribute to meaningful political discussion.

Halpern \& Gibbs (2013) examine the varying affordances of different social media platforms, and consider how users make use of a platforms' affordances in activism and political discussion. The authors showed how Facebook and YouTube's distinct affordances shape the way users partake in political discussion on each platform, suggesting that certain platforms are more conducive to strengthening users' political participation within the public sphere (Halpern \& Gibbs, 2013).

Marichal's (2013) article examines small-scale forms of activism that social media afford, which he calls "micro-activism". Marichal (2013) argues that while micro-activism does not necessarily lead to the political or social mobilization that normally takes place in cyberactivism, it does result in citizens expressing their political identities. This is an important fact because it indicates that minor micro-activism behaviors can add up and contribute to more significant cyberactivist behavior in different settings in the future.

A common theme in the literature supporting the view that social media use in activism is linked to greater participation in the public sphere surrounds how online activism translates into offline activism and political participation. Data from Georgetown University (2016) suggests that people who contribute to a social cause online are also likely to participate in that cause offline, through activities such as volunteering and attending events.

Kwak et al.'s (2018) research suggests that when people perceive social media platforms to be easy to use and have a substantial impact, they are more likely to use social media for political expression. Importantly, they argue that this positive perception of social media influences offline political engagement. The findings of this article are important because they 
show how both online and offline political participation can be influenced by the affordances of social media, which contribute to greater participation in the public sphere.

Valenzuela's (2013) article examines the mechanisms that mediate the relationship between political social media use and offline political participation. In 2011, the author collected survey data about social media use and protest activity in Chile, a time in which Chileans were actively protesting education and energy policies using social media. Valenzuela (2013) found that frequent social media use for the purposes of expressing opinions and joining a cause predicts offline protest activity. However, using social media to keep up with the news was not related to increased offline protest behavior (Valenzuela, 2013).

Finally, multiple scholars have studied prominent cyberactivist movements, analyzing the role that certain social media affordances played in strengthening the movement and allowing citizens' participation in the public sphere. This research highlights how cyberactivism has the potential to widen the public sphere and make a meaningful impact in society today. In her article exploring what motivates activists to utilize hashtags, Konnely (2015) analyzed tweets from the recent \#YesAllWomen and \#HeForShe women's rights movements. The author argues that not only do hashtags allow users to engage with the broader community of an activist movement, they facilitate the formation of collective identity, allowing groups to showcase their particular political ideologies and discourses in a cohesive way (Konnely, 2015).

As discussed earlier, another notable study of a specific cyberactivist movement and its related hashtag comes from scholar Nikita Carney (2016), whose study of the monumental movement and hashtag \#BlackLivesMatter highlights how the use of a visible hashtag can support the participation of typically excluded populations (in this case young black men) in the public sphere. By performing a textual analysis of tweets containing the hashtags 
\#BlackLivesMatter, Carney (2016) argues that social media allows marginalized groups to actively participate within the public sphere, in which they are capable of shaping political discourse and creating meaningful change.

\subsection{Hashtag Feminism}

Hashtag feminism is a recent form of cyberactivism that has become a vital avenue for promoting gender equality and fighting for today's most prominent women's rights issues. Defined as feminist activism that occurs through the use of Twitter hashtags, many feminist scholars have turned their attention to hashtag feminism, studying the important implications of the phenomenon in society today (Clark, 2016).

Dixon (2014) examined how elements of hashtag feminism relate to the formation of emotional connections within activist groups. To Dixon (2014), a sense of connection and loyalty is felt toward the lead hashtag in a feminist movement. In addition, the sharing of personal narratives using the hashtag and retweeting the narratives of others generates a social structure around the hashtag (Dixon, 2014). Dixon (2014) argues that the use of Twitter in hashtag feminism facilitates the formation of community and shared emotions among a collective group.

Through an analysis of \#WhyIStayed, a hashtag that began in response to a 2014 incident surrounding domestic violence in NFL communities, Clark (2016) examined the process in which a feminist hashtag can evolve into a well-known and influential activist movement. The author argues that in general, a hashtag feminist movement is most successful when it unfolds in a pattern similar to a dramatic performance. To Clark (2016), the narratives being shared alongside the hashtag \#WhyIStayed on Twitter closely followed the patterns of a "social drama 
with all the elements of compelling storytelling", which explains the visible success of the movement (p. 800).

Kuo (2018) performed an in-depth analysis of the networks and discourse that exist behind the feminist hashtags \#NotYourAsianSideKick and \#SolidarityisforWhiteWomen. The author suggests that within the dominant feminist counterpublic, there are smaller counterpublics that intersect and connect people of different social identities. In addition, using the method of network analysis, Kuo (2018) argues that hashtags form networks that allow users to "speak across borders and boundaries", and help discussion to spread throughout a larger network (p. 511).

\subsection{Social Network Analysis}

The central method of this project is social network analysis. This section will discuss the intricacies of social network analysis to ensure the reader has a solid grasp of the method in order to understand the research questions in the following section. Social network analysis involves observing and measuring the social relations that exist between individuals and groups within a network as represented by a graphical representation, and drawing inferences from these observations to better understand the relationships within a network (Scott \& Carrington, 2011). Social network analysis can be quantitative or qualitative in nature. To understand the practices of social network analysis in the context of this paper's topic, it is important to define some of the terms and patterns that are particularly relevant for social network analyses used to examine the online social structures formed on social media platforms like Twitter.

In general, a social network is formed when connections, represented as links, ties, or edges, are created between social actors (i.e. individuals or organizations), who are represented 
as nodes (Himelboim et al., 2017). On social media platforms, networks are formed when users interact with each other by forming connections and sharing information. On Twitter specifically, this occurs when users follow, mention, reply and retweet other users.

In network analysis, how nodes are interconnected within a network, and how information flows throughout a network can be characterized by density, centralization, clustering and modularity. Density is a measure of how interconnected individuals are and the rate at which information flows within a network, and is represented by a value between 0 and 1 . In a low density network, users are loosely connected, while in a high density network, users are closely connected. Various studies have shown that within high density networks, information is shared faster between more people (Himelboim et al., 2017).

Another important element of social networks are clusters, which are subsets of nodes within a larger network (Himelboid et al., 2017). On Twitter, clusters are formed when users follow, reply to, and retweet others. Clusters influence how information flows; within clusters, "information flows freely, while across clusters information flow is restricted by the limited connectivity available across clusters" (Himelboid et al., 2017, p. 3). Related to clustering is the modularity of a network, which represents how disconnected clusters are from each other (valued between 0 and 1). Highly modular networks contain two or more clusters that are hardly interconnected, representing a divided network. In these highly modular networks, each distinct cluster can be thought of as representing its own community within the network. In contrast, networks with low modularity contain clusters that are highly interconnected, which form a dense, unified network (Himelboid et al., 2017).

Finally, centralization affects the flow of information in a network, and has been used in studies to represent popularity, power and prestige of an individual or organization (Scott \& 
Carrington, 2011). Centralization is a measure of the average centrality of all nodes within a network, and is valued between 0 and 1 (Gruzd, 2016). A highly centralized network is characterized by a few dominant users or nodes who have a relatively large number of connections. Himelboid et al. (2017) describe this type of network as hierarchical, as these few dominant users can greatly influence the network's information flow. In contrast, in decentralized networks the flow of information is described as egalitarian, as a greater amount of information flows between many users (Himelboid et al., 2017). Related to network centralization is the indegree and outdegree of a node. The indegree centrality of a node is "the number of ties directed to or received by a node" (Gruzd, 2016). Indegree represents the popularity of a user. Outdegree centrality of a node is "the number of ties directed or sent from node to others" (Gruzd, 2016). Outdegree represents influential users who are active participants in their network. 


\section{RESEARCH QUESTIONS}

This major research project will explore the following questions:

RQ1. What do the density, centralization, and modularity of the network say about hashtag feminism in relation to the logic of connective action?

RQ2. What do cluster characteristics (i.e. indegree, outdegree, connections between clusters) reveal about hashtag feminism networks in relation to the logic of connective action?

RQ3. In this network, were feminist hashtags used by members of countermovements? If so, how does this relate to the logic of connective action? 


\section{METHODOLOGY}

The following section will detail how Twitter data was collected in order to explore hashtag feminism, and explains how Social Network Analysis was used to address the research question.

\subsection{Data Collection Approach}

In order to perform a network analysis of patterns surrounding hashtag feminism on Twitter, data was collected from Twitter in the form of individual tweets that contained specific feminist hashtags. Hashtags are keywords or phrases preceded by the symbol '\#', and are used on Twitter and other social media platforms to categorize and tag tweets containing topicspecific content. Hashtags provide users with an easy way to share information and search for tweets about a certain topic. The online program Netlytic (www.netlytic.org) was used to obtain the dataset of tweets. Netlytic is a community-supported text and social network analysis tool that can capture and visualize content from various social media platforms, including tweets from Twitter. Netlytic has a variety of functions that allows its users to perform analyses from their collected data, from textual analysis to network analysis and visualization (Gruzd, 2016). One limitation of Netlytic is that is does not allow the collection of historical data, which is why this project positions itself as an analysis of current patterns of hashtag feminism.

From June 13, 2019 to June 16, 2019, the Netlytic software was used once a day to collect tweets containing the target hashtags \#Feminist, \#Feminism, and/or \#Genderequality. The intent of this project was not to examine one specific sector of hashtag feminism, such as the Women's March or Me Too movements. Rather, the aforementioned hashtags were chosen because they represent more general instances of hashtag feminism that could be included in 
tweets that cover a wide range of feminist subjects. Over four days of using Netlytic to collect data, 3,990 tweets were collected in total, which contained either one, two, or all of the target hashtags.

Once the four days' worth of data were collected, each day of data collection was downloaded as csv files, then combined into a single spreadsheet so that all 3,990 tweets could be visualized as a single network. Then, this spreadsheet was converted to a Google Sheets document so it could be reuploaded to Netlytic for further visual network analysis.

This project acknowledges that due to time frame constraints, the data sample will not be completely free of collection biases. However, a large sample of data (3,990 tweets) was collected over the given data collection time frame in order to bolster the reliability of the results. In addition, in order to avoid sampling bias, this large number of tweets sampled ensured that our sample is representative of the feminist tweets being shared in today's online environment.

\subsection{Method of Analysis}

This paper follows an inductive research approach, and takes on a qualitative rather than quantitative data analysis approach. The method Social Network Analysis (SNA) was used to explore how hashtag feminism occurs on Twitter in relation to the logic of connective action. As mentioned earlier in the literature review section, Social Network Analysis focuses on key network characteristics like density, clustering and modularity, and centralization to examine the social relations between actors in a network.

In order to perform Social Network Analysis on the Twitter data collected, a network visualization was created using Netlytic. For this project, a name network was created to represent the collected data. As opposed to a chain network, name networks are concerned with 
who mentions whom in the network, connecting a Twitter user and any users mentioned in a tweet (Gruzd, 2016). This type of network was chosen because it best represents how Twitter users implementing the hashtags \#Feminist, \#Feminism and \#Genderequality interact with one another. In addition, a distributive recursive layout (DrL), a force-directed graph, was chosen to represent the collected Twitter data because it is ideal for visualizing large networks that contain many nodes (Gruzd, 2016). The DrL network layout is advantageous because it highlights clustering within a network, which is an important network characteristic for this analysis.

The primary focus in analysing the resulting hashtag feminism Twitter network was to examine the main clusters of the network, as well as to look at the connections between clusters in order to gain a better understanding of the central activity and most prominent actors in the network. Thus, after creating the overall network visualization, the analysis focused on the most central part of the network, where the most activity between users existed.

To guide the network analysis, I followed a list of general social network analysis-related questions that could help examine the network of hashtag feminism in relation to the logic of connective action. This paper considers connective action to be evident in hashtag feminism when personal action frames are shared throughout a Twitter network. As mentioned previously, personal action frames involve the sharing of political content in the form of easily personalized ideas (Bennet \& Segerberg, 2012). 


\section{FINDINGS}

In this section, the results of the social network analysis of hashtag feminism on Twitter will be discussed in relation to the logic of connective action. In addition, multiple graphs will be shared to illustrate certain findings from the analysis. For the readers' reference, in the network visualizations, nodes (Twitter users) are represented as circles, while lines are edges, which represent communication between Twitter users, in the form of a mention or reply.

5.1 RQ1: "What do the density, centralization, and modularity of the network say about hashtag feminism in relation to the logic of connective action?"

This section will address and analyze the network properties of the overall Twitter hashtag feminism network (see Figure 1), as highlighted in Social Network Analysis (SNA). The density of the network was found to be 0.0050 , representing a low density network. This means that overall, Twitter users who implemented the target feminist hashtags during the given data collection period are only loosely connected. In other words, there is a relatively small amount of information flowing amongst Twitter users in the entire network.

The modularity of the network is very high, with a value of 0.9452 . The high modularity of the network confirms that the clusters within the graph are substantially disconnected. Although from Figure 1 it is clear that a few of the larger, more central clusters are somewhat interconnected, the overall high modularity implies that information flow throughout the entire network is limited. In general, Twitter users who implement feminist hashtags do not tend to interact with many other hashtag feminists outside of their immediate networks.

The centralization value of the overall network is 0.0082 , representing low centralization. Unlike a highly centralized, hierarchical network in which a small number of actors influence the 
flow of information, this hashtag feminism network is more egalitarian, meaning the flow of information is influenced by many Twitter users in the network. As such, although this network is highly modular, the decentralized, egalitarian nature of the network may suggest that users do not need to be particularly popular or have a large influence in order to share information with many other users.

Figure 1: Overall hashtag feminism Twitter network

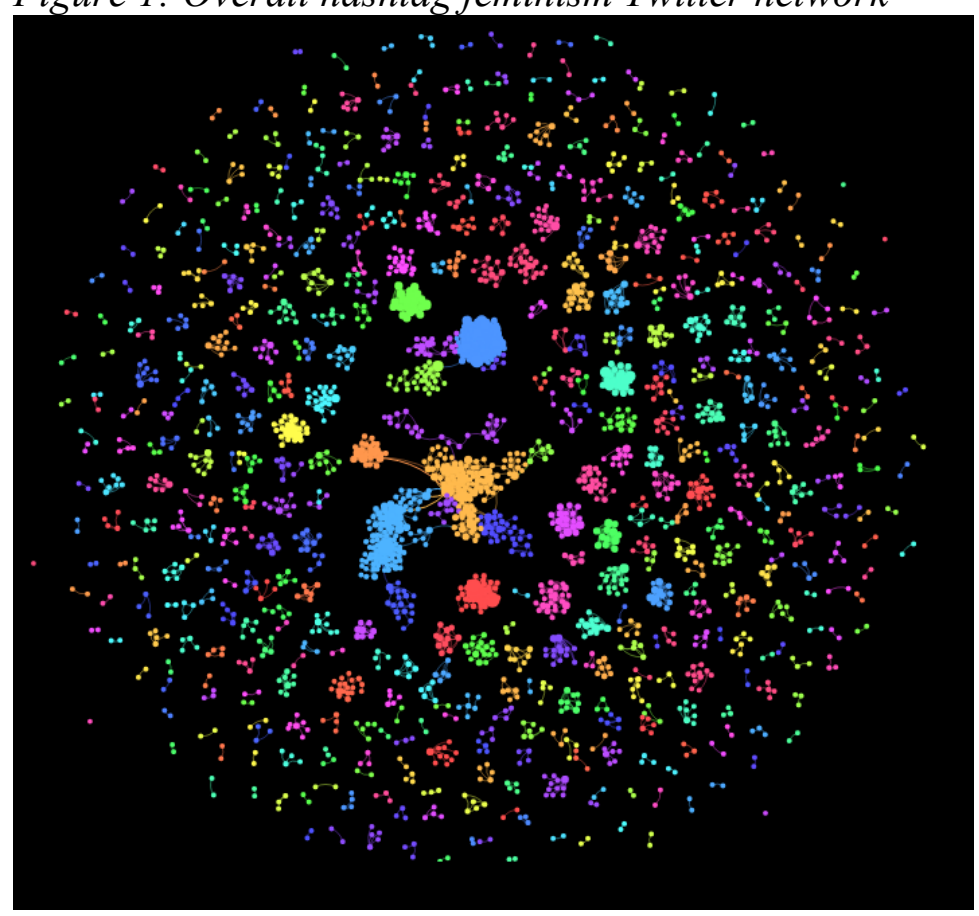

Important aspects of connective action are revealed by the network analysis properties of the overall hashtag feminism network. Firstly, the high degree of modularity in the overall network suggests that when people post tweets containing feminist hashtags along with personal action frames or politically-driven content, these posts tend to be shared among Twitter users in close vicinity to the original poster. In the logic of connective action, participating in political discussion and taking action involves personal expression and the sharing of "ideas and actions in trusted relationships" (Bennet \& Segerberg, 2012, p.753). This points towards why feminist 
hashtags linked to personal and political discourses tend to be shared within distinct, smaller clusters of Twitter users within the posters' immediate network.

Secondly, the low degree of centralization in the overall hashtag feminist Twitter network reveals how a wide variety of Twitter users are making use of the target hashtags, either sharing their own personal action frames or spreading others. Although there are a few highly centralized clusters, suggesting that some Twitter users linked to feminist hashtags have more popularity than others, the overall low centralization of the network suggests that feminist hashtags are being used outside of the networks immediately surrounding the most popular Twitter accounts. In addition, the low centralization of the overall network may suggest that social media technologies do not allow connective action networks to scale up as much as Bennet \& Segerberg (2012) have suggested. Rather, when Twitter users implement feminist hashtags, the resulting connective action produced between other Twitter users may stay within the Twitter users immediate network.

Finally, the low desity of the network reveals that personal action frames are not being shared very widely between many users throughout the overall hashtag feminist network, again suggesting that the social media platform provided by Twitter may not encourage connective action networks to scale up as Bennet \& Segerberg (2012) have claimed.

5.2 RQ2. "What do cluster characteristics (i.e. indegree, outdegree, connections between clusters) reveal about hashtag feminist networks in relation to the logic of connective action?" Examining the characteristics of the dominant clusters in the network reveals a lot about how hashtag feminism operates on Twitter in relation to the logic of connective action. For instance, taking a closer look at the indegree and outdegree of each cluster sheds light on the role 
of individuals versus organizations in collective action networks. On Netlytic, the graph visualization can be changed to represent either the indegree or outdegree of each Twitter user. Using this function allows the viewer to explore how a network changes based on the number of messages a Twitter user receives (indegree) or the number of messages a Twitter user shares (outdegree) (see Figure 2). In each of the 3 largest clusters in the network (see Figure 3), the nodes/Twitter users with the highest indegree are organizations. These organizations are the most popular or prominent Twitter users in their given clusters, and in the overall network, as they have received the highest number of messages from other Twitter users. These three most popular/prominent organizations are @vaastavngo, a men's rights activist organization based in Mumbai, India; @women deliver, an organization based in New York City advocating for gender equality and women's rights; and @un_women, a United Nations organization for women's empowerment and equality (Twitter, 2019). The prominence and popularity of organizations in tweets about hashtag feminism (as demonstrated by high indegree value) provides evidence that based on Bennet \& Segerberg's (2012) typology of connective action networks, hashtag feminism may encourage the formation of organizationally enabled networks. In other words, organizations, rather than individual users, influence how hashtag feminists share personal action frames. Organizations can use their principal position in the network to engage individuals and facilitate the production of connective action. In addition, the fact that organizations have the highest indegree in the network's top three clusters indicates that organizations have greater influence on the conversation surrounding hashtag feminism. 
Figure 2: Comparison of visualization based on indegree vs. outdegree

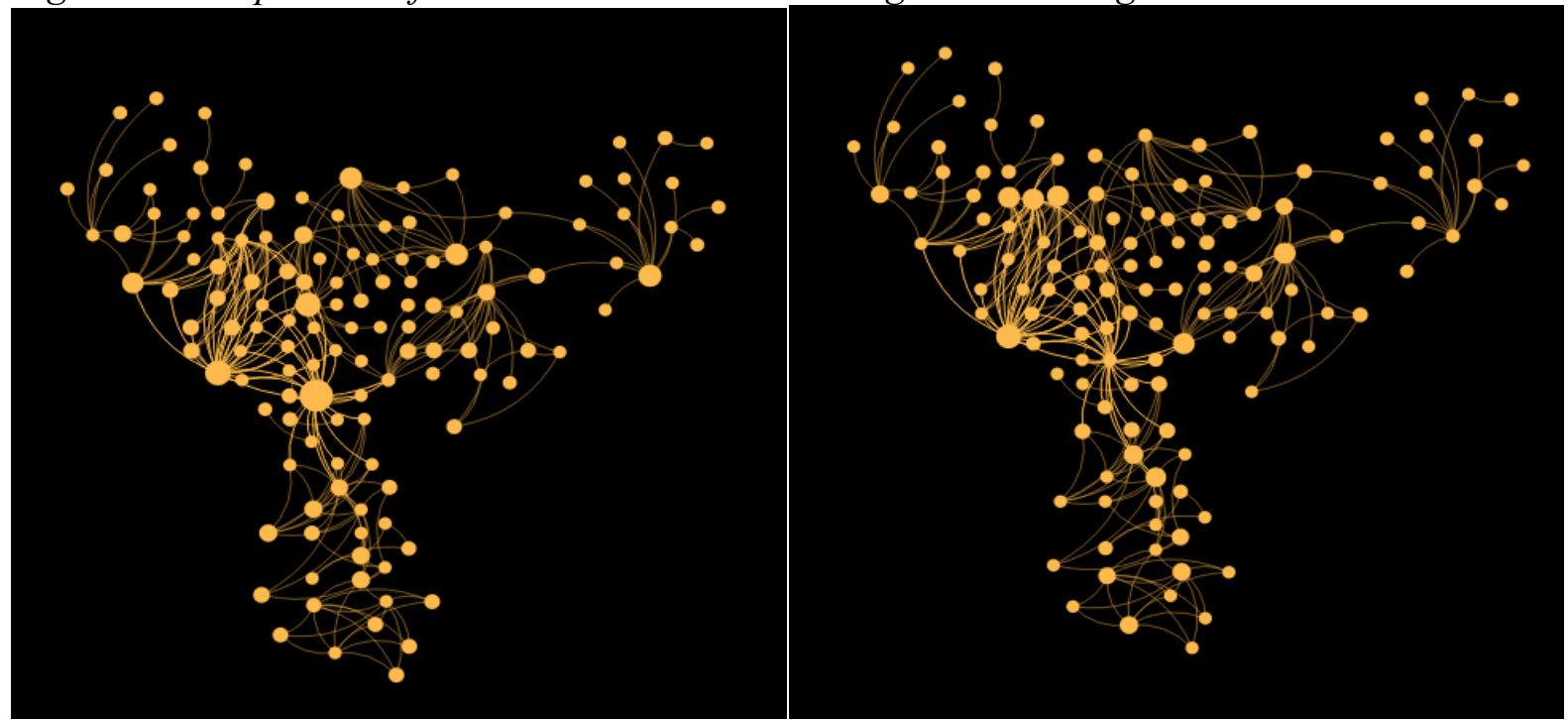

From left to right: Cluster 2 visualized based on indegree; Cluster 2 visualized based on outdegree.

Figure 3: Main clusters in the overall hashtag feminism Twitter network

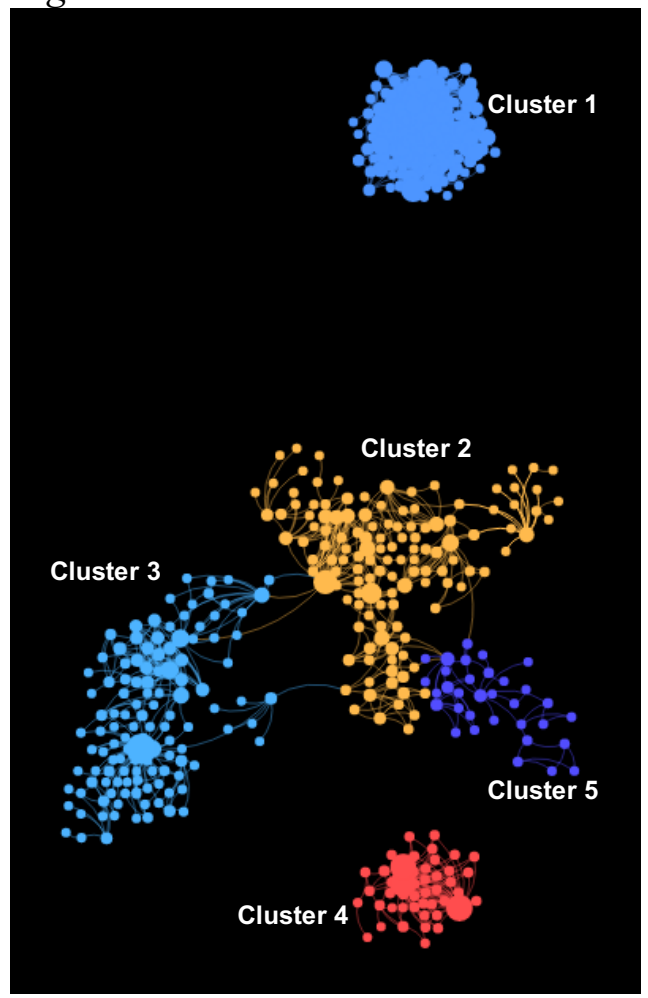


Further, it appears that within the hashtag feminism network, dominant Twitter accounts that span clusters (i.e. connect two or more clusters together) tend to be organizations. For example, in Figure 4, it can be observed that the Twitter account @un_women (an organization), is mentioned by 44 users in cluster 3 , but is also mentioned by Twitter users from a smaller nearby cluster. The fact that organizations' connections are more likely to span across clusters points towards the likelihood that prominent organizations can exert influence on the spread of feminist hashtags throughout smaller networks. Additionally, the dominant role of these organizations, both within clusters and in connecting clusters, suggests that organizations may take on a 'brokerage' role, using their dominant position to interconnect Twitter users involved in different conversations.

Figure 4: Connections across clusters - @un_women mentioned by users in cluster 3, as well as a nearby cluster

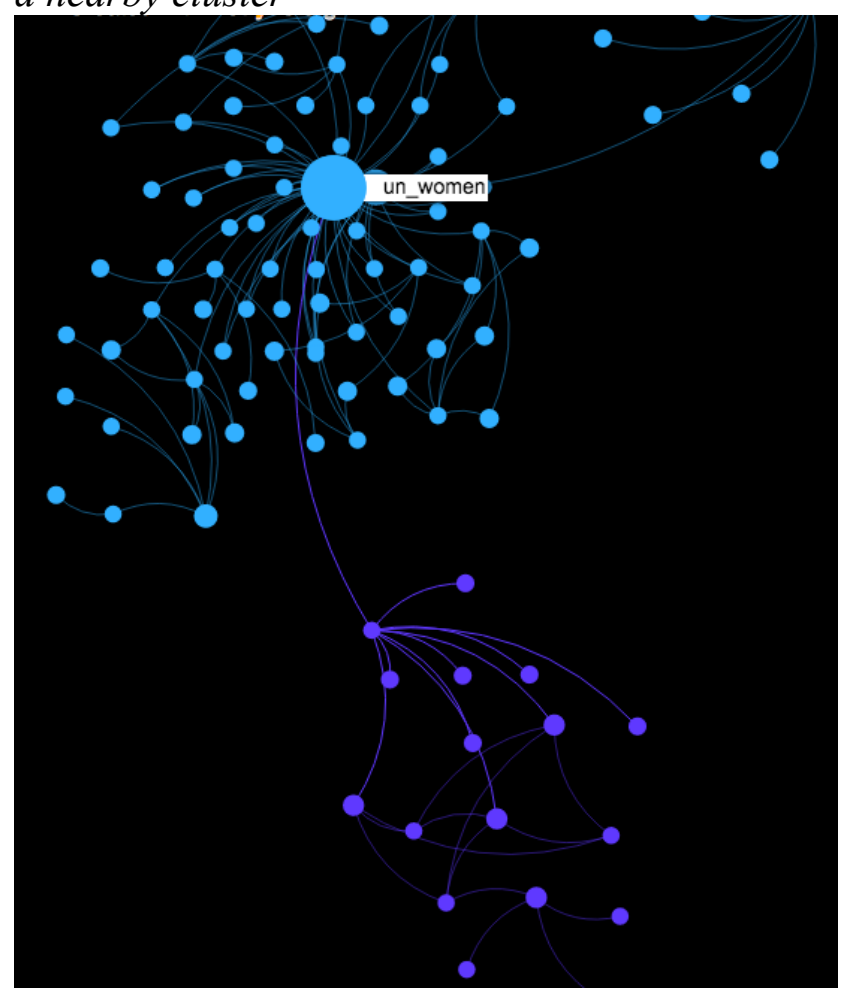


Next, in the 3 largest clusters in the hashtag feminism Twitter network, the nodes with the highest outdegree are a mix of individuals and organizations. Users with the highest outdegree value send the greatest number of tweets to other Twitter accounts, which signifies that these are the most active participants or influential individuals in the network. The three most active users in the largest clusters in the network are @love_a_man, an individual and men's rights activist; @katja_iversen, an individual who is the president and CEO of @womendeliver; and @heforshe, a global organization advocating for gender equality (Twitter, 2019). Because the Twitter accounts with the highest outdegree are a mix of individuals and organizations, it is difficult to assess whether the Twitter activity of individuals or organizations is more influential in facilitating connective action. However, it is clear that both individuals and organizations are capable of playing an important role in sharing message content associated with feminist hashtags to many users in their networks.

5.3 RQ3. "In this network, were feminist hashtags used by members of countermovements? If so, how does this relate to the logic of connective action?"

Taking a closer look at the demographics and tweet content of one of the three largest clusters in the network reveals how feminist hashtags are not always used for their intended purposes, which has important implications for connective action. As mentioned earlier, the users in cluster 1 with the highest indegree and outdegree are @ vaastavngo and @love_a_man, respectively. By searching for these accounts on Twitter, it was found that both accounts describe themselves as "men's rights activists" in the Twitter 'biography' section of their profiles (Twitter, 2019). Men's rights activism is described as a backlash countermovement against feminism, based on the idea that certain social issues and policies structurally discriminate 
against men (Maddison, 1999). The two aforementioned Twitter accounts are included in the hashtag feminism network because their Twitter activity is linked to the target hashtags \#feminism, \#feminist, and/or \#genderequality. However, examining activity within this cluster shows that many Twitter users make use of feminist hashtags to introduce and spread messages that run counter to the ideological basis of hashtag feminism. For example, one user in this cluster,@himanshu0070070 tweeted:

“@mkoirala You probably haven’t googled what \#Feminism is all about in the present times. If people are saying \#FeminismisCancer, find out why they say it before gladly announcing your joining the feminist bandwagon. \#MenToo" (Twitter, 2019).

In this particular tweet, the hashtag \#feminism is used, although the remaining content of the tweet is decidedly anti-feminist, imploring the user to consider the negative aspects of feminism before joining the movement. This tweet exemplifies that through the same mechanisms that produce connective action in hashtag feminism, some countermovement Twitter users implement feminist hashtags to gain entry into feminist networks, and facilitate the spreading of countermovement ideologies.

This use of feminist hashtags to bring attention to a men's rights countermovement is interesting to consider in relation to network analysis and connective action, as they reveal how the countermovement's strategy was unsuccessful. Firstly, the men's rights activism Twitter network in cluster 1 is extremely dense, which means that the Twitter users within this cluster are very closely connected (see Figure 5). However, in comparison to the other main clusters, cluster 1 is relatively isolated from other clusters in the overall Twitter network. Thus, although the men's rights countermovement present in cluster 1 made use of feminist hashtags in an attempt to gain access to the feminist Twitter network and spread their ideology throughout it, 
their clusters relative disconnection from the rest of the network is evidence that it was not successful in doing so.

Figure 5: High density of cluster 1 (Men's rights counterprotest group example)

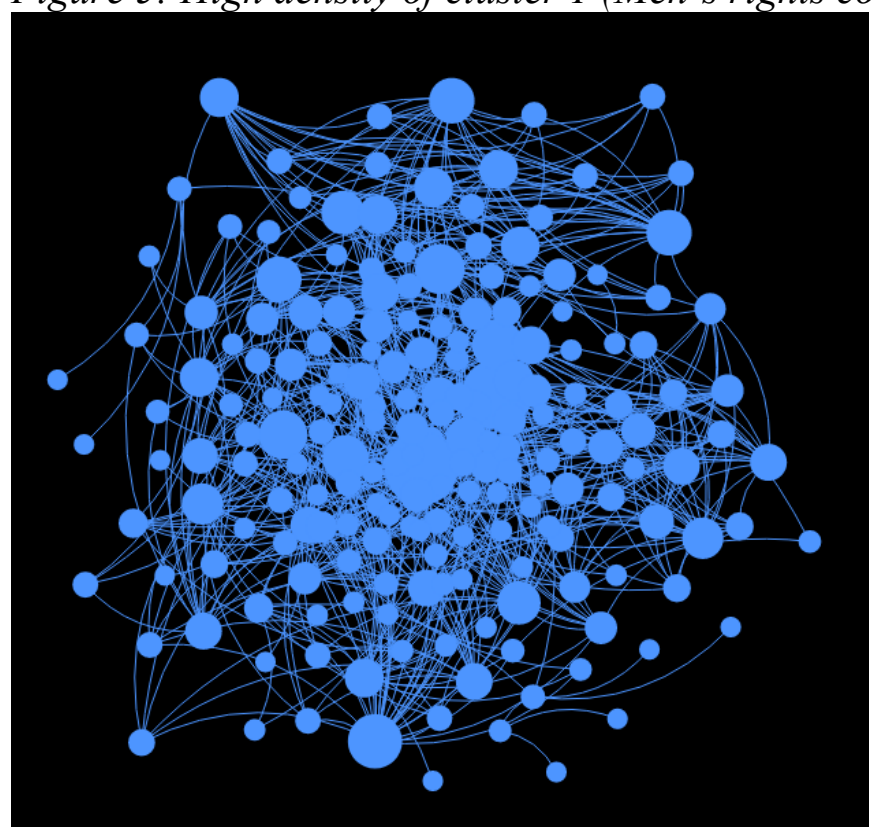

One possible reason the men's rights countermovement was unsuccessful in penetrating the feminist hashtag network could be because the countermovement was not strong enough to produce connective action. A central reason that hashtag feminism has been so successful and produces connective action is because many feminist hashtags encourage the sharing of personal action frames, or people's personal narratives of experiences surrounding gender equality issues (Bennet \& Segerberg, 2012). As previously mentioned, this sharing of personal action frames is what produces connective action. However, when the men's rights countermovement attempted to spread their counter-ideology through the Twitter network of hashtag feminism, they likely were not tweeting personal action frames that would facilitate the production of enough connective action to provide them with sufficient influence to infiltrate the connective action 
networks of hashtag feminism. Rather, the tweets sent out by men's rights activists in cluster 1 tended to be more informational in nature. For example, @sandeepsn29 tweeted:

"Join \#MenToo movement in huge number on this Saturday, 15th June 2019 at \#AzadMaidan Mumbai for \#GenderEquality \& Celebrate \#FathersDay2019 by donating blood to \#ThalassaemiaChildPatients @vaastavngo @Dev_Fadnavis@iHrithik@cskkanu@timesofindia@dna \#FakeCases \#GenderBiasedLaws”.

@Sandeepsn29's above tweet exemplifies how the men's rights activists found in cluster 1 tend to make use of Twitter. These tweets tend to contain information attempting to mobilize individuals and promote different countermovement-related events. In addition, men's rights countermovement Twitter users tend to @ tag a large number of users, in an attempt to spread their message to more users. It is obvious that the content of these tweets tends to contrast the personal action frame content characteristic of hashtag feminist tweets, providing solid evidence for why these countermovement tweets do not produce connective action. 


\section{CONCLUSION}

This major research project aimed to explore hashtag feminism in relation to connective action logic. To answer this paper's research questions, social network analysis was used to examine the Twitter networks that form when Twitter users implement the target hashtags \#Feminism, \#Feminist, and \#Genderequality. The analysis showed that the overall hashtag feminism network found on Twitter is characterized by low density and centralization, and high modularity. Many distinct, disconnected clusters of hashtag feminists exist within the Twitter network, showing that many different groups of Twitter users are making use of feminist hashtags. However, minimal connection occurs between these groups. Importantly, the findings revealed the dominant role of organizations in hashtag feminism Twitter networks, providing evidence that hashtag feminism produces connective action via organizationally enabled networks. Specifically, organizations were found to be the most prominent users in each cluster, as they received the highest number of messages from other Twitter users that contained feminist hashtags. In addition, the Twitter users that connected two or more clusters within the network together tended to be organizations, revealing how organizations often play a 'brokerage' role, using their dominance to interconnect Twitter users involved in different hashtag feminist-related discussions. Finally, it was found that within the hashtag feminist Twitter network, counteractivists such as Men's Rights activists make use of feminist hashtags to proliferate countermovement ideologies through hashtag feminist networks. However, it was found that the aforementioned countermovement was not successful at producing connective action, as demonstrated by the clear disconnect between the countermovements' cluster from other clusters in the overall hashtag feminism Twitter network. 
The findings discovered from the network analysis provide a solid basis for understanding how hashtag feminism relates to the advanced participation of feminists in the public sphere. Firstly, the above-mentioned research findings indicating that many different clusters of Twitter users make use of feminist hashtags provides evidence that the social media platform Twitter acts as what Fraser (1991) defines as a counterpublic. It can be argued that Twitter provides an alternative space outside of the primary public sphere in which feminists, as well as anti-feminists, can produce and participate in discourses that represent their interests and identities.

Secondly, this project's analysis of the feminist hashtag network provides interesting insight into how feminists can strategically participate in hashtag feminism in order to further participate in the public sphere. Given the findings from RQ2, which suggest that organizations tend to hold the most dominant role in hashtag feminism Twitter networks, feminists can piggyback on this dominance of organizations to strengthen and spread their discourse and ideology throughout the larger network. This could occur in a number of different ways. For example, hashtag feminists may collaborate with well-established organizations by asking the organization to 'retweet' certain posts so that it reaches a much more expansive audience of Twitter users. In addition, to advance their discourse within the larger sphere, feminists should @ mention well-known organizations that have a large number of followers in their tweets. As observed from the network analysis of hashtag feminism on Twitter, when Twitter users mentioned prominent organizations like @un_women in their tweets, they were able to connect with a larger number of clusters within the overall network. Thus, mentioning dominant organizations in their tweets could allow feminists to better spread counter-discourses within the primary public sphere. 
To conclude, the social network analysis performed in this study provided a considerable amount of insight into how hashtag feminism operates in relation to the logic of connective action. Overall, this study provides an interesting analysis of hashtag feminism, an emerging form of cyberactivism that allows the everyday citizen to connect with others, share their own personal narratives, and participate in an activist cause they might not otherwise have access to without social media. However, future studies could focus on various related topics that were beyond the scope of this project. For example, future research could use content analysis to examine the precise mechanisms that determine whether hashtag feminism advances the role of women in the public sphere. Alternatively, future studies could explore why organizations hold such a prominent role in hashtag feminism Twitter networks, and consider the implications of this prominence of organizations on the role of individuals in activism. In addition, future studies could question how the hashtag of a cyberactivist movement intersects with other social movements or counterpublics. Finally, as social media platforms and technology in general continue to evolve, it will be extremely interesting to observe and study how activism evolves. As such, future research may examine how the use of feminist hashtags evolve over time. 


\section{BIBLIOGRAPHY}

Bennet, W. L., Segerberg, A. (2012). The logic of connective action: Digital media and the personalization of contentious politics. Information, Communication \& Society, 15(5). Retrieved from https://journals-scholarsportalinfo.ezproxy.lib.ryerson.ca/pdf/1369118x/v15i0005/739_tloca.xml

Carney, N. (2016). All Lives Matter, but so Does Race: Black Lives Matter and the Evolving Role of Social Media. Humanity \& Society, 40(2). Retrieved from https://journals-sagepubcom.ezproxy.lib.ryerson.ca/doi/full/10.1177/0160597616643868?utm_source=summon\&utm medium=discovery-provider

Charles, G., Fuentes-Rohwer, L. (2015). Habermas, the public sphere, and the creation of a racial counterpublic. Michigan Journal of Race \& Law. 21(1). Retrieved from https://search-proquestcom.ezproxy.lib.ryerson.ca/docview/1778700558/fulltextPDF/ABBA815F1B184D0DPQ/1?acco untid $=13631$

Christensen, H. S. (2011). Political activities on the Internet: Slacktivism or political participation by other means? First Monday, 16(2). Retrieved from https://firstmonday.org/article/view/3336/2767

Clark, R. (2016). "Hope in a hashtag": the discursive activism of \#WhyIStayed. Feminist Media Studies, 16(5). Retrieved from https://journals-scholarsportalinfo.ezproxy.lib.ryerson.ca/pdf/14680777/v16i0005/788_iahtdao.xml

Dixon, K. (2014). Feminist online identity: Analyzing the presence of hashtag feminism. Journal of Arts \& Humanities, 3(7). Retrieved from

https://theartsjournal.org/index.php/site/article/view/509/286

Flinchum, J. R., Kruse, L. M., Norris, D. (2018). Social Media as a Public Sphere? Politics on Social Media. The Sociological Quarterly, 59(1). Retrieved from https://journals-scholarsportalinfo.ezproxy.lib.ryerson.ca/details/00380253/v59i0001/62_smaapsposm.xml

Fraser, N. (1990). Rethinking the Public Sphere: A Contribution to the Critique of Actually Existing Democracy. Social Text, 26. Retrieved from https://www-jstororg.ezproxy.lib.ryerson.ca/stable/466240?seq=1\#page_scan_tab_contents

Georgetown University (2016). Dynamics of Cause Engagement [PDF document]. Retrieved from http://csic.georgetown.edu/wp-content/uploads/2016/12/dynamics-cause-engagement.pdf

Gibbs, J., Halpern, D. (2013). Social media as a catalyst for online deliberation? Exploring the affordances of Facebook and YouTube for political expression. Computers in Human Behavior, 
29(3). Retrieved from https://www-sciencedirect-

com.ezproxy.lib.ryerson.ca/science/article/pii/S0747563212002762

Gil-Garcia, J. R., Sandoval-Almazan, R. (2014). Towards cyberactivism 2.0? Understanding the use of social media and other information technologies for political activism and social movements. Government Information Quarterly, 31(3). Retrieved from https://www.sciencedirect.com/science/article/pii/S0740624X14000902

Gruzd, A. (2016). Netlytic: Software for Automated Text and Social Network Analysis. Available at http://Netlytic.org

Habermas, J. (1991). A Structural Transformation of the Public Sphere. Cambridge, MA: MIT Press.

Himelboid, I., Smith, M., Rainie, L., Shneirderman, B., Espina, C. (2017). Classifying Twitter Topic-Networks Using Social Network Analysis. Social Media + Society, 3(1). Retrieved from https://journals-sagepub-com.ezproxy.lib.ryerson.ca/doi/pdf/10.1177/2056305117691545.

Konnely, A. (2015). \#Activism: Identity, Affiliation, and Political Discourse-Making on Twitter. The Arbutus Review, 6(1). Retrieved from

https://journals.uvic.ca/index.php/arbutus/article/view/15070/6010

Kuo, R. (2018). Racial justice activist hashtags: Counterpublics and discourse circulation. new media + society, 20(2). Retrieved from https://journals-scholarsportalinfo.ezproxy.lib.ryerson.ca/pdf/14614448/v20i0002/495_rjahcadc.xml

Kwak, N., Lane, D., Weeks, B., Hee Kim, D., Lee, Slgi, Bachleda, S. (2018). Perceptions of Social Media for Politics: Testing the Slacktivism Hypothesis. Human Communication Research, 44(2). Retrieved from https://academic.oup.com/hcr/article-abstract/44/2/197/4957051

Lyba, R. (2017). Exploring UK Millenials' Social Media Consumption Patterns and Participation in Elections, Activism, and "Slacktivism". Social Sciences Computer Review, 35 (4). Retrieved from https://journals-sagepub-com.ezproxy.lib.ryerson.ca/doi/pdf/10.1177/0894439316655738

Maddison, S. (1999). Private Men, Public anger: The Men's Rights Movement in Australia. Journal of Interdisciplinary Gender Studies, 4(2). Retrieved from https://web.archive.org/web/20131020163216/https://newcastle.edu.au/Resources/Schools/Huma nities\%20and\%20Social\%20Science/JIGS/JIGSV4N2_039.pdf

Marichal, J. (2013). Political Facebook groups: Micro-activism and the digital front stage. First Monday, 18(12). Retrieved from https://firstmonday.org/ojs/index.php/fm/article/view/4653/3800 
McLaughlin, L. (1993). Feminism, the public sphere, media and democracy. Media, Culture and Society, 15. Retrieved from https://journals-scholarsportalinfo.ezproxy.lib.ryerson.ca/pdf/01634437/v15i0004/599_ftpsmad.xml

Scott, J. \& Carrington, P. (2011). Social Network Analysis: An Introduction. The SAGE Handbook of Social Network Analysis. London, UK: Sage Publications Ltd.

Shirky, C. (2016). The Political Power of Social Media: Technology, the Public Sphere, and Political Change. Foreign Affairs, 90(1). Retrieved from

https:/warwick.ac.uk/fac/arts/theatre_s/current/postgraduate/ma-theatre-performance-research2017/option_modules/th988/schedule/shirky.pdf

Valenzuela, S. (2013). Unpacking the Use of Social Media for Protest Behavior: The Roles of Information, Opinion Expression, and Activism. American Behavioral Scientist, 57(7). Retrieved from http://journals.sagepub.com.ezproxy.lib.ryerson.ca/doi/pdf/10.1177/0002764213479375 